

open research

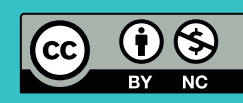

\section{Oesophageal pressure as a surrogate of pleural pressure in mechanically ventilated patients}

\author{
Antoine Tilmont ${ }^{1,2}$, Benjamin Coiffard ${ }^{1,2}$, Takeshi Yoshida ${ }^{3,4}$, Florence Daviet ${ }^{1,2}$, \\ Karine Baumstarck ${ }^{2}$, Geoffrey Brioude ${ }^{5}$, Sami Hraiech ${ }^{1,2}$, Jean-Marie Forel ${ }^{1,2}$, \\ Antoine Roch ${ }^{1,6}$, Laurent Brochard ${ }^{4,7}$, Laurent Papazian ${ }^{1,4}$ and \\ Christophe Guervilly ${ }^{1,4}$
}

Affiliations: ${ }^{1}$ Médecine Intensive Réanimation, Hôpital Nord, AP-HM, Marseille, France. ${ }^{2}$ Faculté de Médecine, Centre d'Etudes et de Recherches sur les Services de Santé et Qualité de Vie EA 3279, Aix-Marseille Université, Marseille, France. ${ }^{3}$ Dept of Anesthesiology and Intensive Care Medicine, Osaka University Graduate School of Medicine, Suita, Japan. ${ }^{4}$ Pleural Pressure Working Group (PLUG) - Acute Respiratory Failure Section of the European Society of Intensive Care Medicine, Brussels, Belgium. ${ }^{5}$ Dept of Thoracic Surgery and Oesophageal Diseases, Hôpital Nord, AP-HM, Marseille, France. ${ }^{6}$ Service des Urgences, Hôpital Nord, AP-HM, Marseille, France. ${ }^{7}$ Interdepartmental Division of Critical Care Medicine, University of Toronto, Keenan Research Centre, Li Ka Shing Knowledge Institute, St Michael's Hospital, Toronto, ON, Canada.

Correspondence: Christophe Guervilly, Médecine Intensive Réanimation, Hôpital Nord, Chemin des Bourrely, 13015 Marseille, France. E-mail: christophe.guervillydap-hm.fr

\section{ABSTRACT}

Background: Oesophageal pressure $\left(P_{\text {oes }}\right)$ is used to approximate pleural pressure $\left(P_{\mathrm{pl}}\right)$ and therefore to estimate transpulmonary pressure $\left(P_{\mathrm{L}}\right)$. We aimed to compare oesophageal and regional pleural pressures and to calculate transpulmonary pressures in a prospective physiological study on lung transplant recipients during their stay in the intensive care unit of a tertiary university hospital.

Methods: Lung transplant recipients receiving invasive mechanical ventilation and monitored by oesophageal manometry and dependent and nondependent pleural catheters were investigated during the post-operative period. We performed simultaneous short-time measurements and recordings of oesophageal manometry and pleural pressures. Expiratory and inspiratory $P_{\mathrm{L}}$ were computed by subtracting regional $P_{\mathrm{pl}}$ or $P_{\text {oes }}$ from airway pressure; inspiratory $P_{\mathrm{L}}$ was also calculated with the elastance ratio method.

Results: 16 patients were included. Among them, 14 were analysed. Oesophageal pressures correlated with dependent and nondependent pleural pressures during expiration $\left(R^{2}=0.71, p=0.005\right.$ and $R^{2}=0.77, p=0.001$, respectively) and during inspiration $\left(\mathrm{R}^{2}=0.66\right.$ for both, $\mathrm{p}=0.01$ and $\mathrm{p}=0.014$, respectively). $P_{\mathrm{L}}$ values calculated using $P_{\text {oes }}$ were close to those obtained from the dependent pleural catheter but higher than those obtained from the nondependent pleural catheter both during expiration and inspiration.

Conclusions: In ventilated lung transplant recipients, oesophageal manometry is well correlated with pleural pressure. The absolute value of $P_{\text {oes }}$ is higher than $P_{\mathrm{pl}}$ of nondependent lung regions and could therefore underestimate the highest level of lung stress in those at high risk of overinflation.

@ERSpublications

During controlled ventilation without respiratory muscle activity, absolute oesophageal pressure is higher than the pleural pressure of the nondependent lung regions and could therefore underestimate the highest level of lung stress in that lung https://bit.ly/3a95CUh

Cite this article as: Tilmont A, Coiffard B, Yoshida T, et al. Oesophageal pressure as a surrogate of pleural pressure in mechanically ventilated patients. ERJ Open Res 2021; 7: 00646-2020 [https:// doi.org/10.1183/23120541.00646-2020].

This study is registered at www.clinicaltrials.gov with identifier number NCT03179644. Data sharing is available for other researchers who provide a methodological plan on a reasonable request to the corresponding author.

This article has supplementary material available from openres.ersjournals.com

Received: 4 Sept 2020 | Accepted after revision: 2 Dec 2020

Copyright $\odot$ ERS 2021. This article is open access and distributed under the terms of the Creative Commons Attribution Non-Commercial Licence 4.0. 


\section{Introduction}

Mechanical ventilation for acute respiratory distress syndrome (ARDS) is still challenging. Recent guidelines have established strong recommendations for using low tidal volume $\left(V_{\mathrm{t}}\right)\left(4-8 \mathrm{~mL} \cdot \mathrm{kg}^{-1}\right.$ predicted bodyweight) and limiting plateau pressure $\left(P_{\text {plat }}\right)$ [1]. Concerning the level of positive end-expiratory pressure (PEEP) to apply, notably there is no well-established recommendation to use a high level of PEEP for patients with the most severe ARDS. Based on a previous pilot study [2], some experts recommend to set PEEP using oesophageal manometry by targeting the transpulmonary plateau pressure. Oesophageal pressure $\left(P_{\text {oes }}\right)$ has been used for decades by physiologists as a surrogate of pleural pressure $\left(P_{\mathrm{pl}}\right)$ measurement and allows the calculation of the true lung distending pressure, the so-called transpulmonary pressure, $P_{\mathrm{L}}=P_{\mathrm{aw}}-P_{\text {oes}}$, where $P_{\mathrm{aw}}$ is the airway pressure [3]. However, there are controversies about using the absolute value of $P_{\text {oes }}$ and some authors recommend to consider the tidal variation of oesophageal pressure which allows the calculation of the ratio of the elastance of the chest wall to the respiratory system [4].

Recently, in a ventilated lung-injured pig model and a human cadaver ventilated model, YosHIDA et al. [3] have conciliated these two theories through comparisons of dependent and nondependent pleural pressures to oesophageal pressure. The main results of the Yoshida et al. [3] study are that $P_{\text {oes }}$ accurately estimates the dependent pleural pressure both at inspiratory and expiratory pressures, and that elastance-derived inspiratory transpulmonary pressure accurately estimates the nondependent inspiratory transpulmonary pressure.

Therefore, the objective of this study was to compare $P_{\text {oes }}$ with dependent and nondependent pleural pressures in lung transplant recipients receiving invasive mechanical ventilation during the post-operative period. Our hypothesis is that transpulmonary pressure calculated with $P_{\text {oes }}$ could underestimate the regional $P_{\mathrm{L}}$ of the nondependent lung.

\section{Methods}

Study design, setting and participants

This study was conducted in the intensive care unit (ICU) of the North University Hospital (Marseille, France). According to French legislation, all patients gave their written informed consent to participate. The study was registered at ClinicalTrials.gov with identifier number NCT03179644 on 7 June 2017 and approved by the local ethics committee (Comité de Protection des Personnes Sud Méditerranée; 2016-A00567-44).

Patient were included if they fulfilled the following inclusion criteria: age $\geqslant 18$ years admitted in the ICU after double-lung transplantation and mechanically ventilated. Exclusion criteria were: age <18 years, pregnancy or breastfeeding, lack of medical insurance, deprivation of liberty by a judicial or administrative decision, those hospitalised without consent, single-lung transplantation and contraindication to placement of a nasogastric tube (oesophageal varices, oesophageal cancer, surgery of the oesophagus $<1$ year). Patients were not included in case of admission in the ICU with an open chest after surgery and/or high-flow air leaks ( $>10 \%$ of inspired volume) or if they had systemic sclerosis with oesophageal involvement.

\section{Pleural pressure measurements}

Before chest closure, the thoracic surgeon introduced multihole pleural catheters (Pleurocath; Plastimed, Le Plessis Bouchard, France) along the thoracic drains under direct view. The nondependent catheters were positioned at the surface of the anterior visceral pleura; the dependent catheters were positioned at the surface of the posterior visceral pleura (supplementary figure S1). According to surgical considerations, two or four pleural catheters were positioned on the right and/or left side, at least one to measure the dependent pleural pressure and one to measure the nondependent pleural pressure per patient. Before measurement, we verified catheter emptiness with $5 \mathrm{~mL}$ of air. Chest tubes were then clamped during measurements. Pleural catheters were thereafter connected to a pressure port of a Fluxmed monitor (MBMED, Martínez, Argentina). Good transmission of pleural pressure was assessed by an occlusion test. We performed 3-5-min recordings for each pleural tracing during the first $48 \mathrm{~h}$ post-operative period.

\section{Oesophageal pressures measurements}

An oesophageal balloon catheter (Nutrivent; Sidam, Mirandola, Italy) was inserted and inflated with a minimal, nonstress volume $(2-3 \mathrm{~mL})$ of air as recommended [4]. Adequate positioning of the balloon in the lower part of the oesophagus was confirmed by the presence of cardiac artefacts on the oesophageal curve and a positive occlusion test (expiratory hold on the ventilator) under passive conditions with gentle chest compression [5]. Oesophageal pressure was recorded by the same device used for pleural pressure recordings. The occlusion test was considered positive if the relationship between $\Delta P_{\mathrm{pl}}$ and $\Delta P_{\mathrm{aw}}$, as well as 
between $\Delta P_{\text {oes }}$ and $\Delta P_{\mathrm{aw}}$, yielded a slope of $1.0 \pm 0.2$. In case of a negative test, tracings and measurements were not analysed. Measurements were performed under static conditions (zero flow) during an end-inspiratory occlusion pause of $2 \mathrm{~s}$ allowing the measurement of $P_{\text {plat }}$ and inspiratory $P_{\text {oes }}\left(P_{\text {oes,insp }}\right)$, respectively, and following an end-expiratory occlusion pause of $5 \mathrm{~s}$ allowing the measurement of total $\operatorname{PEEP}\left(\mathrm{PEEP}_{\text {tot }}\right)$ and expiratory $P_{\text {oes }}\left(P_{\text {oes,exp }}\right)$, respectively.

\section{Definitions and calculations}

The following formulae were used for assessment of transpulmonary pressures.

Inspiratory transpulmonary pressure $\left(P_{\mathrm{L}, \text { insp }}\right)$ was determined using oesophageal pressure as $P_{\mathrm{L}, \text { insp,oes }}$ $=P_{\text {plat }}-P_{\text {oes,insp }}$ or using direct measurement of $P_{\mathrm{pl}}$ in the nondependent lung as $P_{\mathrm{L}, \mathrm{ND} \text {,insp }}=P_{\mathrm{plat}}-P_{\mathrm{pl}, \mathrm{ND} \text {,insp }}$ and in the dependent lung as $P_{\mathrm{L}, \mathrm{D}, \text { insp }}=P_{\text {plat }}-P_{\mathrm{pl}, \mathrm{D} \text {,insp. }}$.

Conversely, expiratory transpulmonary pressure $\left(P_{\mathrm{L}, \exp }\right)$ was determined using oesophageal pressure as $P_{\mathrm{L}, \exp , \text { oes }}=\mathrm{PEEP}_{\text {tot }}-P_{\text {oes,exp }}$ or using direct measurement of $P_{\mathrm{pl}}$ in the nondependent lung as $P_{\mathrm{L}, \mathrm{ND} \text {,exp }}=$ $\mathrm{PEEP}_{\text {tot }}-P_{\mathrm{pl}, \mathrm{ND} \text {,exp }}$ and in the dependent lung as $P_{\mathrm{L}, \mathrm{D}, \exp }=\mathrm{PEEP}_{\text {tot }}-P_{\mathrm{pl}, \mathrm{D} \text {,exp }}$.

Additionally, $P_{\mathrm{L} \text {,insp }}$ was also calculated from the elastance ratio of the chest wall to the respiratory system [6] as $P_{\mathrm{L}, \text { insp, ER }}=P_{\text {plat }}-\left(P_{\text {plat }} \times \mathrm{EL}_{\mathrm{CW}} / \mathrm{EL}_{\mathrm{RS}}\right)$. Accordingly, respiratory system elastance $\left(\mathrm{EL}_{\mathrm{RS}}\right)=$ $\left(P_{\text {plat }}-\mathrm{PEEP}_{\text {tot }}\right) / V_{\mathrm{t}}$ and chest wall elastance $\left(\mathrm{EL}_{\mathrm{CW}}\right)=\left(P_{\text {oes,insp }}-P_{\text {oes,exp }}\right) / V_{\mathrm{t}}$.

All pressures were expressed in $\mathrm{cmH}_{2} \mathrm{O}$.

\section{Statistical analysis}

As this was an exploratory physiological study, no statistical power calculation was anticipated. However, the ethics committee approval allowed the enrolment of a maximum of 45 patients during a 2-year period. All presented results are part of the primary analysis of the data. All statistics were analysed by two-tailed tests. Continuous variables were reported as mean with standard deviation or median with interquartile range as appropriate. Comparisons were performed by the t-test or Mann-Whitney test as appropriate. Categorical variables were expressed as the absolute value and percentage. Comparisons were performed by the Chi-squared test. Normality of the distribution of variables was tested by Kolmogorov-Smirnov and Shapiro-Wilk tests. Correlations were determined with the Pearson correlation test with further Bland-Altman analysis for each correlation. A two-way repeated-measures ANOVA was performed to compare transpulmonary pressures at end-expiration and end-inspiration according to the modality of calculation and to the level of applied PEEP. The normality of the distribution of the residuals, the assumption of sphericity, and the interaction between transpulmonary pressures and PEEP were checked. Intra-group differences were evaluated by post hoc Bonferroni pairwise multiple comparisons. A p-value $<0.05$ was retained as significant. SPSS version 20.0 (IBM, Armonk, NY, USA) was used for all statistical analyses and figures.

\section{Results}

\section{Patients and measurements}

22 lung transplant recipients gave their informed consent before surgery (figure 1). Six patients were excluded; 16 lung transplant recipients were monitored. Two of these patients were not analysed because of a negative occlusion test (correlations between $\Delta P_{\text {oes }}$ and $\Delta P_{\mathrm{aw}}$ and/or $\Delta P_{\mathrm{pl}}$ and $\Delta P_{\mathrm{aw}}<0.8$ ). The main characteristics of the 14 remaining patients are shown in table 1 . Illustrative tracings of volume, flow and pressures during an occlusion test with chest compression are shown in figure $2.50 \%$ of patients were assisted by venovenous extracorporeal membrane oxygenation at ICU admission. All measurements were performed while patients were sedated and mechanically ventilated in volume-assisted controlled mode with a range of PEEP between 8 and $14 \mathrm{cmH}_{2} \mathrm{O}$ without spontaneous breathing effort. Among the 14 patients, four had daily serial measurements totalling 24 measurements. Details of gas exchange, mechanical ventilation settings and respiratory system mechanics are given in table 2.

\section{Correlations between oesophageal and pleural pressures}

Occlusions tests yielded $0.95 \pm 0.05$ for $\Delta P_{\text {oes }} / \Delta P_{\text {aw }}$ and $0.94 \pm 0.06$ for $\Delta P_{\mathrm{pl}} / \Delta P_{\mathrm{aw}}$. Dependent and nondependent expiratory pleural pressures were significantly correlated with expiratory oesophageal pressure $\left(\mathrm{R}^{2}=0.71\right.$ and $\mathrm{R}^{2}=0.77$, respectively, $\mathrm{p}<0.01$ ) (figure $3 \mathrm{a}$ and $\mathrm{c}$ ). Dependent and nondependent inspiratory pleural pressures were significantly correlated with inspiratory oesophageal pressure $\left(\mathrm{R}^{2}=0.66\right.$ for each, $\mathrm{p}<0.05$ ) (figure $4 \mathrm{a}$ and $\mathrm{c}$ ). Oesophageal pressure was always found to be higher than nondependent pleural pressure. During expiration time, the mean $\pm \mathrm{sD}$ difference between oesophageal pressure and dependent pleural pressure was $0.48 \pm 2.87 \mathrm{cmH}_{2} \mathrm{O}$ and between oesophageal pressure and nondependent pleural pressure was $5.25 \pm 2.51 \mathrm{cmH}_{2} \mathrm{O}$ (figure $3 \mathrm{~b}$ and $\mathrm{d}$ ). During inspiration time, the mean \pm SD difference between oesophageal pressure and dependent pleural pressure was $0.98 \pm 2.90 \mathrm{cmH}_{2} \mathrm{O}$ 


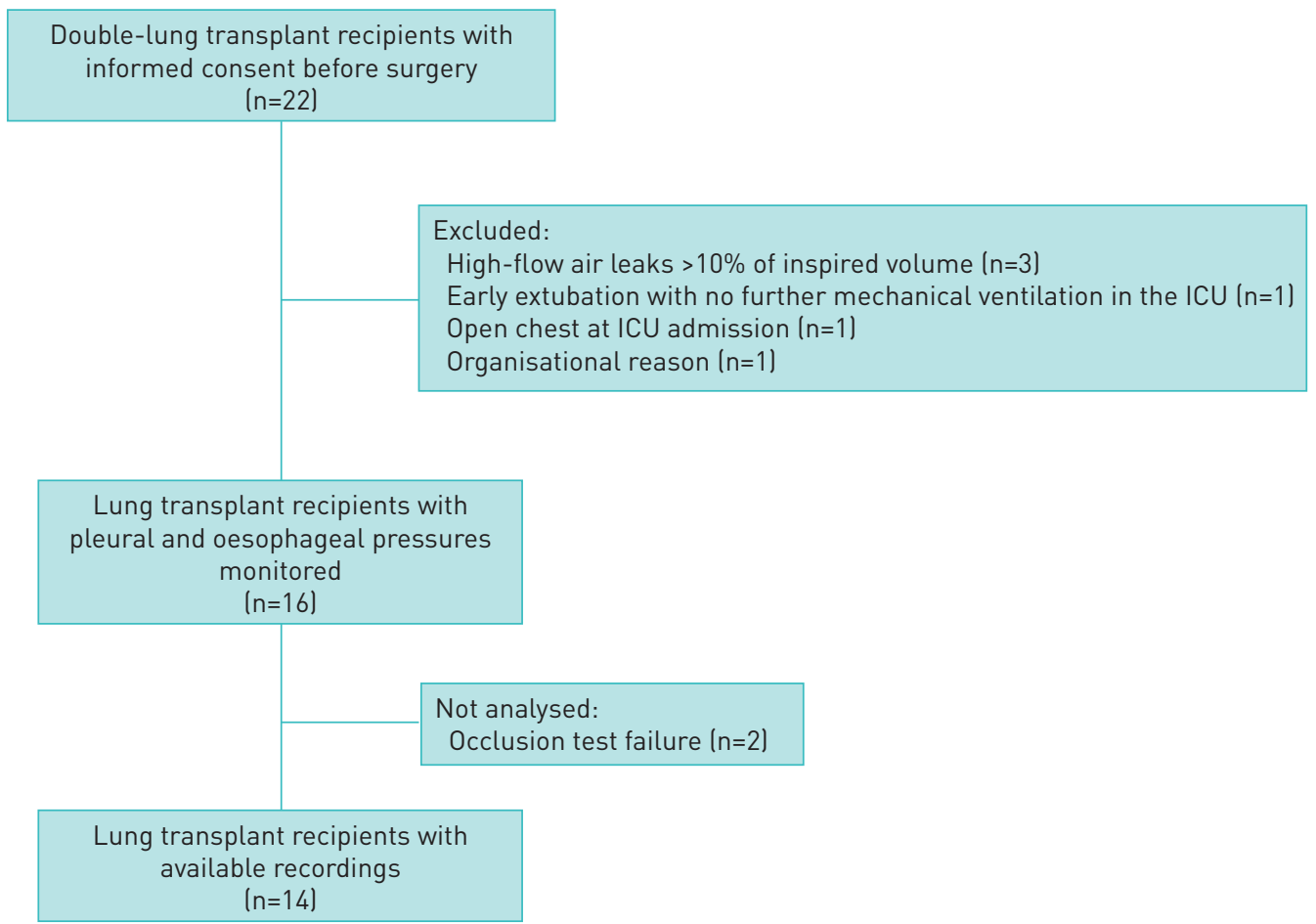

FIGURE 1 Flow diagram of the included patients. ICU: intensive care unit.

and between oesophageal pressure and nondependent pleural pressure was $6.09 \pm 2.90 \mathrm{cmH}_{2} \mathrm{O}$ (figure $4 \mathrm{~b}$ and $\mathrm{d}$ ). The mean $\pm \mathrm{sD}$ difference between dependent pleural pressure and nondependent pleural pressure was $4.76 \pm 2.94 \mathrm{cmH}_{2} \mathrm{O}$ at expiratory time and $5.38 \pm 2.11 \mathrm{cmH}_{2} \mathrm{O}$ at inspiratory time.

\section{Correlations between transpulmonary pressures}

Correlations and Bland-Altman analysis between inspiratory transpulmonary pressures according to four ways of calculation are presented in figure 5. Inspiratory $P_{\mathrm{L}}$ computed from oesophageal pressure was

\section{TABLE 1 Patient characteristics}

\begin{tabular}{|c|c|c|c|c|c|c|c|c|c|}
\hline Subject & $\begin{array}{l}\text { Age } \\
\text { years }\end{array}$ & Sex & $\begin{array}{l}\text { SOFA score at } \\
\text { inclusion }\end{array}$ & $\begin{array}{l}\text { SAPS II score } \\
\text { at inclusion }\end{array}$ & $\begin{array}{l}\text { Indication } \\
\text { for DLT }\end{array}$ & vvECMO & $\begin{array}{c}\text { Duration of } \\
\text { mechanical } \\
\text { ventilation days }\end{array}$ & $\begin{array}{l}\text { ICU length } \\
\text { of stay days }\end{array}$ & $\begin{array}{c}\text { ICU } \\
\text { survival }\end{array}$ \\
\hline 2 & 61 & Male & 7 & 55 & Fibrosis & Yes & 41 & 50 & Yes \\
\hline 3 & 41 & Male & 7 & 40 & Fibrosis & No & 3 & 9 & Yes \\
\hline 4 & 69 & Male & 6 & 39 & Fibrosis & No & 1 & 7 & Yes \\
\hline 7 & 65 & Male & 11 & 58 & Fibrosis & Yes & 5 & 5 & No \\
\hline 8 & 62 & Male & 5 & 46 & Fibrosis & No & 5 & 13 & Yes \\
\hline 9 & 64 & Male & 7 & 39 & Fibrosis & No & 5 & 13 & Yes \\
\hline 10 & 61 & Female & 11 & 51 & COPD & Yes & 90 & 90 & Yes \\
\hline 11 & 53 & Male & 9 & 48 & Fibrosis & Yes & 6 & 10 & Yes \\
\hline 12 & 62 & Female & 7 & 50 & COPD & No & 43 & 47 & Yes \\
\hline
\end{tabular}

SOFA: Sequential Organ Failure Assessment; SAPS: Simplified Acute Physiology Score; DLT: double-lung transplantation; vvECMO: venovenous extracorporeal membrane oxygenation; ICU: intensive care unit; COPD: chronic obstructive pulmonary disease. \#: at ICU admission. 


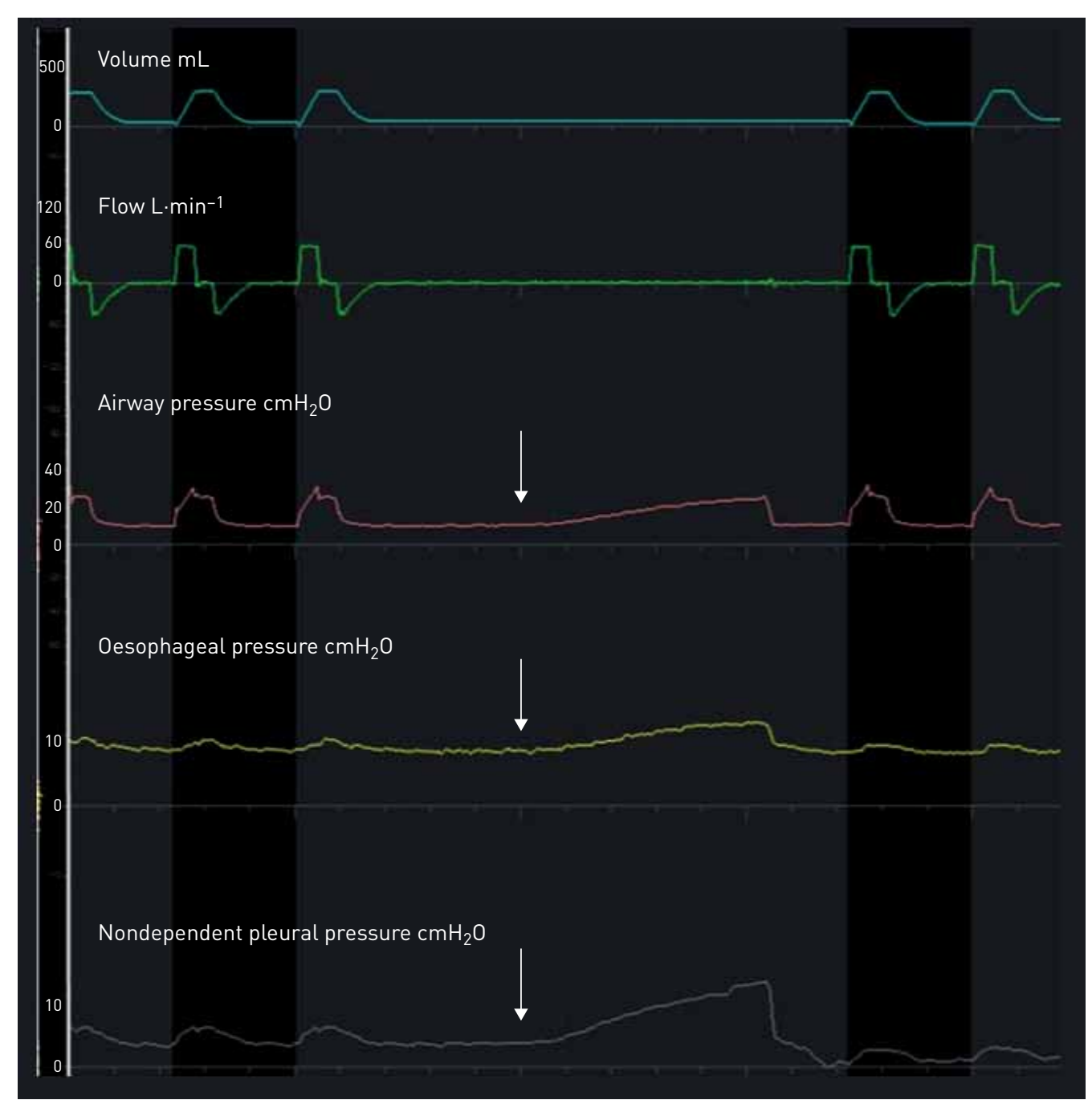

FIGURE 2 Representative tracings of volume, flow, and airway, oesophageal and nondependent pleural pressures during an occlusion test. The increase of airway, oesophageal and nondependent pleural pressures of the same magnitude during gentle thoracic compression (white arrows) ensures the correct placement of the pleural catheter and oesophageal balloon.

better correlated with inspiratory $P_{\mathrm{L}}$ calculated from dependent and nondependent pleural pressures than those calculated from the elastance ratio method $\left(R^{2}=0.604, R^{2}=0.629\right.$ and $R^{2}=0.45$, respectively, $\mathrm{p}<0.05)$ [6]. However, the estimated bias was higher between $P_{\mathrm{L} \text {,insp,oes }}$ and $P_{\mathrm{L}, \mathrm{ND} \text {,insp }}$ than between $P_{\mathrm{L} \text {,insp,oes }}$ and $P_{\mathrm{L}, \mathrm{D} \text {,insp }}\left(-6.00 \pm 3.94\right.$ and $-1.61 \pm 3.62 \mathrm{cmH}_{2} \mathrm{O}$, respectively). Correlations and Bland-Altman analysis between expiratory transpulmonary pressures according to three ways of calculation are presented in figure 6. Expiratory $P_{\mathrm{L}}$ computed from oesophageal pressure was modestly correlated with expiratory $P_{\mathrm{L}}$ calculated from dependent and nondependent pleural pressures $\left(\mathrm{R}^{2}=0.479\right.$ and $\mathrm{R}^{2}=0.531$, respectively, $\mathrm{p}<0.02)$. However, the agreement was better between $P_{\mathrm{L}, \exp , o e s}$ and $P_{\mathrm{L}, \mathrm{D}, \exp }$ than between $P_{\mathrm{L}, \exp , \text { oes }}$ and $P_{\mathrm{L}, \mathrm{ND} \text {,exp }}$ (estimated bias $-1.34 \pm 3.32$ and $-5.55 \pm 3.36 \mathrm{cmH}_{2} \mathrm{O}$, respectively).

\section{Relationship between expiratory transpulmonary pressures at different PEEP levels}

Expiratory transpulmonary pressures calculated using $P_{\text {oes }}$ were close to those obtained from the dependent pleural catheter (figure 7a). Expiratory transpulmonary pressures calculated with the nondependent pleural catheter $\left(P_{\mathrm{L}, \mathrm{ND} \text {,exp }}\right)$ were higher than those calculated from both the dependent catheter $\left(P_{\mathrm{L}, \mathrm{D}, \mathrm{exp}}\right)$ and oesophageal pressure $\left(P_{\mathrm{L}, \text { exp,oes }}\right)$ whatever the PEEP level. We also found a significant interaction between PEEP and $P_{\mathrm{L}, \exp }\left(\mathrm{R}^{2}=0.301, \mathrm{p}=0.02\right)$.

\section{Relationship between inspiratory transpulmonary pressures at different PEEP levels}

Inspiratory transpulmonary pressures calculated using $P_{\text {oes }}$ were close to those directly measured by the dependent pleural catheter (figure $7 \mathrm{~b}$ ). Inspiratory transpulmonary pressures calculated from the elastance 


\section{TABLE 2 Gas exchange, mechanical ventilation settings and respiratory system mechanics}

\begin{tabular}{|c|c|c|c|c|c|c|c|c|c|c|}
\hline Subject & $P_{\mathrm{aO}_{2}} / F_{\mathrm{IO}_{2}}$ & $\mathrm{pH}$ & $\begin{array}{c}P_{\mathrm{acO}_{2}} \\
\mathrm{mmHg}\end{array}$ & $\begin{array}{c}\text { Tidal } \\
\text { volume } \\
\text { mL }\end{array}$ & $\begin{array}{c}\text { Plateau } \\
\text { pressure } \\
\mathrm{cmH}_{2} \mathrm{O}\end{array}$ & $\begin{array}{l}\text { PEEP } \\
\mathrm{cmH}_{2} \mathrm{O}\end{array}$ & $\begin{array}{c}\text { Driving } \\
\text { pressure } \\
\mathrm{cmH}_{2} \mathrm{O}\end{array}$ & $\begin{array}{c}\text { Respiratory } \\
\text { system } \\
\text { elastance } \\
\mathrm{cmH}_{2} \mathrm{O} \cdot \mathrm{L}^{-1}\end{array}$ & $\begin{array}{l}\text { Chest wall } \\
\text { elastance } \\
\mathrm{cmH}_{2} \mathrm{O} \cdot \mathrm{L}^{-1}\end{array}$ & $\begin{array}{c}\text { Elastance } \\
\text { ratio }\end{array}$ \\
\hline 1 & 60 & 7.35 & 40 & 340 & 28 & 12 & 16 & 47 & 7 & 0.15 \\
\hline 2 & 346 & 7.26 & 30 & 270 & 21 & 10 & 11 & 41 & 21 & 0.51 \\
\hline 3 & 184 & 7.41 & 41 & 334 & 22 & 10 & 12 & 36 & 17 & 0.47 \\
\hline 4 & 388 & 7.39 & 35 & 443 & 22 & 8 & 14 & 32 & 8 & 0.25 \\
\hline 5 & 200 & 7.29 & 34 & 250 & 27 & 14 & 13 & 52 & 11 & 0.21 \\
\hline 6 & 157 & 7.49 & 33 & 383 & 25 & 10 & 15 & 39 & 3 & 0.08 \\
\hline 7 & 65 & 7.30 & 50 & 284 & 31 & 15 & 16 & 56 & 9 & 0.16 \\
\hline 8 & 150 & 7.30 & 78 & 358 & 26 & 10 & 16 & 44 & 4 & 0.09 \\
\hline 9 & 160 & 7.34 & 49 & 417 & 16 & 5 & 11 & 26 & 6 & 0.23 \\
\hline 10 & 90 & 7.36 & 39 & 200 & 24 & 10 & 14 & 70 & 18 & 0.26 \\
\hline 11 & 126 & 7.30 & 37 & 222 & 26 & 14 & 12 & 54 & 8 & 0.15 \\
\hline 12 & 140 & 7.36 & 41 & 321 & 29 & 14 & 15 & 47 & 5 & 0.11 \\
\hline 13 & 225 & 7.42 & 32 & 460 & 23 & 14 & 9 & 20 & 12 & 0.60 \\
\hline 14 & 250 & 7.38 & 36 & 400 & 25 & 12 & 13 & 32 & 8 & 0.25 \\
\hline Mean士sD & $181 \pm 96$ & $7.35 \pm 0.06$ & $41 \pm 12$ & $334 \pm 81$ & $25 \pm 4$ & $11 \pm 3$ & $13 \pm 2$ & $42 \pm 13$ & $10 \pm 5$ & $0.25 \pm 0.16$ \\
\hline
\end{tabular}
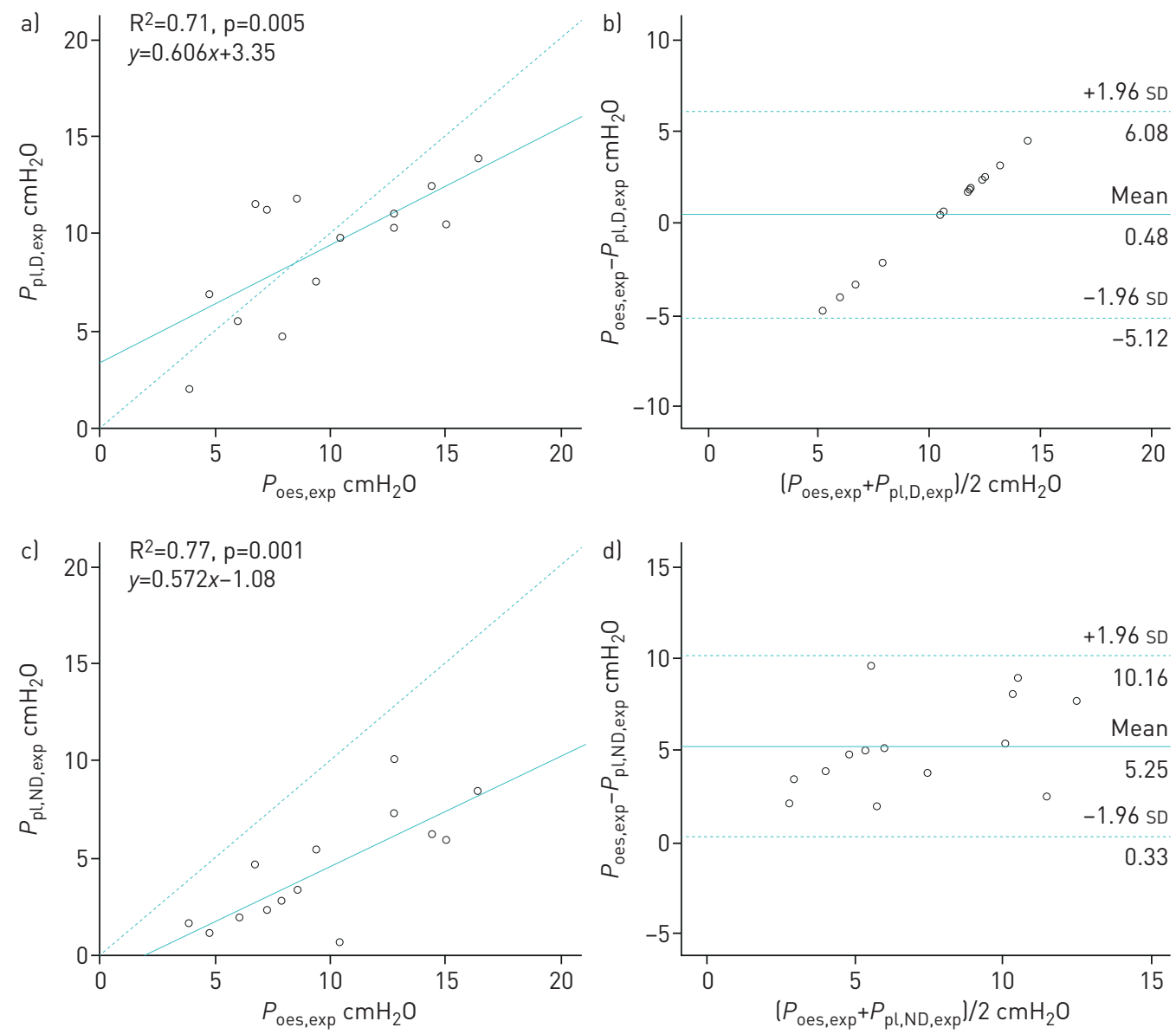

FIGURE 3 a, c) Correlations and b, d) Bland-Altman analysis between a, b) dependent and c, d) nondependent pleural pressures and oesophageal pressure at end-expiration. a, c) Dashed line represents the identity line. $b$, d) Solid and dashed lines represent mean \pm 1.96 SD of the differences. Each circle represents a different patient. 

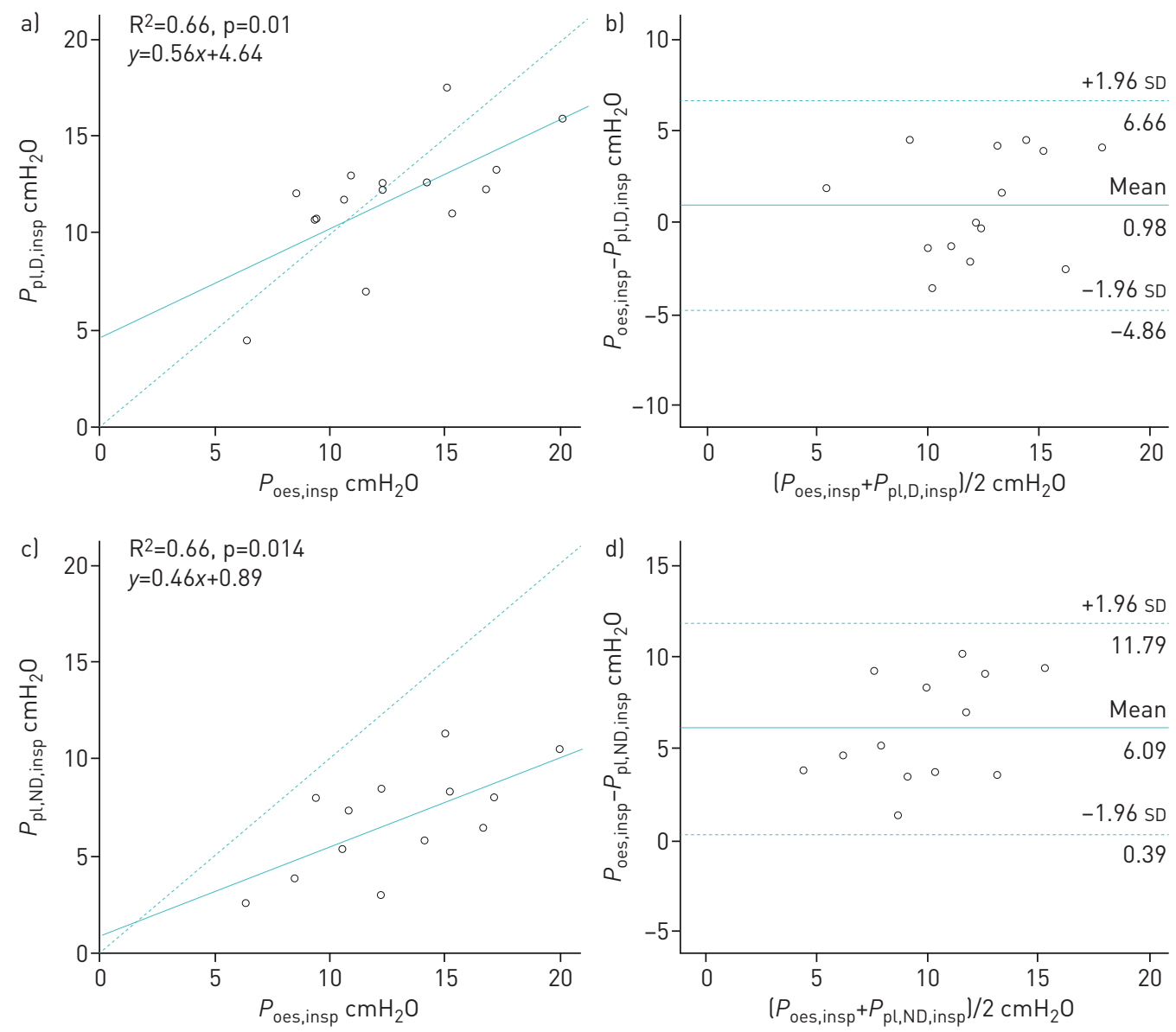

FIGURE 4 a, c) Correlations and b, d) Bland-Altman analysis between a, b) dependent and c, d) nondependent pleural pressures and oesophageal pressure at end-inspiration. a, c) Dashed line represents the identity line. $b$, d) Solid and dashed lines represent mean \pm 1.96 SD of the differences. Each circle represents a different patient.

ratio of the chest wall to the respiratory system $\left(P_{\mathrm{L}, \text { insp,ER }}\right)$ were also close to those measured using the nondependent pleural catheter $\left(P_{\mathrm{L}, \mathrm{ND} \text {,insp }}\right)$. In our model, $P_{\mathrm{L} \text {,insp,oes }}$ underestimates the true regional transpulmonary pressure of the nondependent lung region $\left(P_{\mathrm{L}, \mathrm{ND} \text {,insp }}\right)$. We did not find any interaction between PEEP and $P_{\mathrm{L} \text {,insp }}\left(\mathrm{R}^{2}=0.132, \mathrm{p}=0.203\right)$.

\section{Discussion}

In this mechanically ventilated in vivo human model, $P_{\text {oes }}$ is close to the pleural pressures of the dependent lung region. However, we found overestimation by $P_{\text {oes }}$ using nondependent lung region pleural pressures. Therefore, the limitation of inspiratory lung stress using $P_{\text {oes }}$ may lead to underestimating lung stress in nondependent lung regions. Rather, inspiratory $P_{\mathrm{L}}$ calculated with the elastance ratio $\left(P_{\mathrm{L}, \text { insp,ER }}\right)$ may reflect local lung stress in nondependent lung regions, which are usually the overinflated lung regions.

From previous clinical and experimental studies, we know that 1) because of the weight of the heart and the increase of the gravitational gradient of pleural pressure during ARDS, $P_{\text {oes }}$ is higher in supine patients ventilated for ARDS than those of nonventilated healthy subjects in the upright position $[2,7,8]$, and 2) from an experimental study in dogs [9], and recently in humans [10], it was demonstrated that absolute pleural pressures are $\sim 7 \mathrm{cmH}_{2} \mathrm{O}$ lower than $P_{\text {oes }}$ in the nondependent regions and $\sim 5 \mathrm{cmH}_{2} \mathrm{O}$ higher in the dependent regions at low intrathoracic pressure. Therefore, some authors have proposed to apply a correction subtraction of between 2.5 and $5 \mathrm{cmH}_{2} \mathrm{O}$ to the actual measured oesophageal pressure to calculate the transpulmonary pressure $[8,9,11]$. However, the utility of a fixed correction of absolute transpulmonary pressure is still debated $[12,13]$.

A previous experimental study has demonstrated that in anesthetised pigs and human cadavers 1) $P_{\text {oes }}$ was midway between $P_{\mathrm{pl}}$ in the dependent region and $P_{\mathrm{pl}}$ in the nondependent region, and 2) elastance-derived transpulmonary pressure matched the directly measured transpulmonary pressure from nondependent regions [3]. 
a)

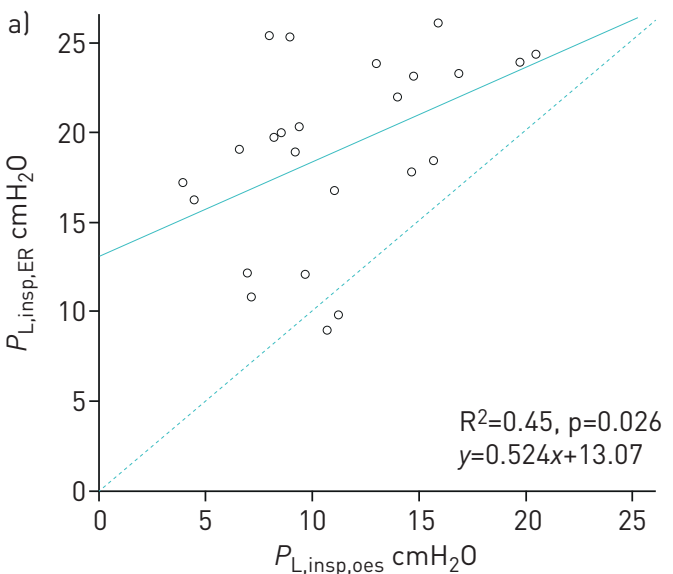

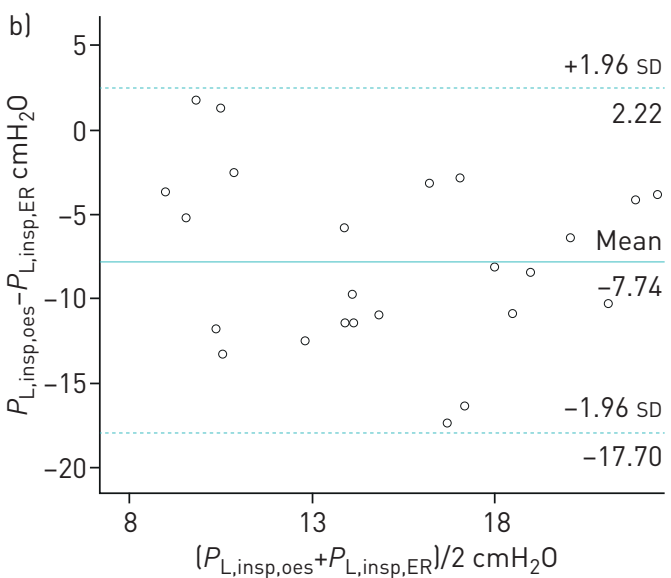

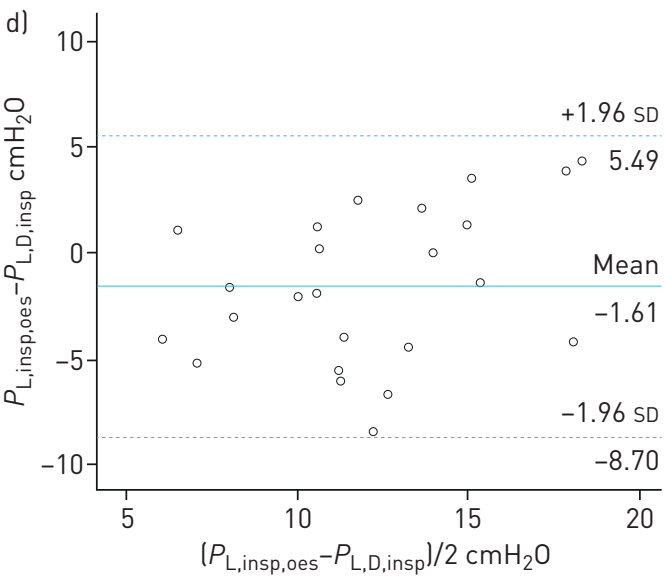


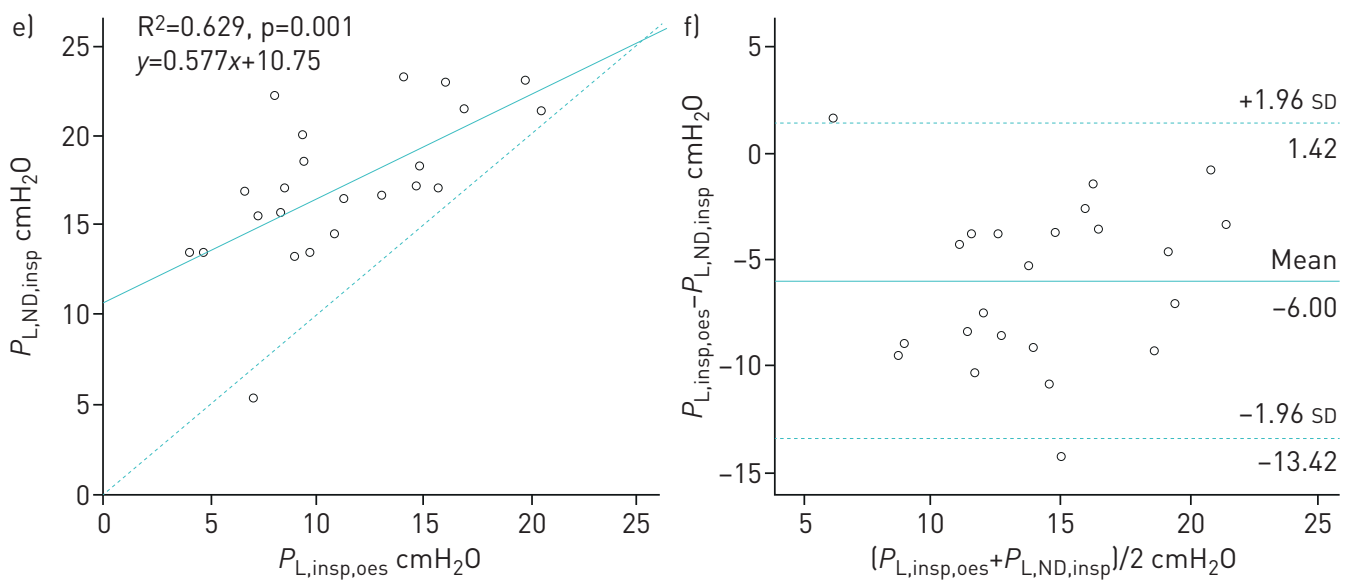

FIGURE 5 a, c, el Correlations and b, d, f) Bland-Altman analysis between transpulmonary pressures calculated using a, b) elastance ratio, c, d) dependent pleural pressure and e, f) nondependent pleural pressure during end-inspiration. a, c, e) Dashed line represents the identity line. b, d, f) Solid and dashed lines represent mean \pm 1.96 SD of the differences. Each circle represents a different patient.

In addition, Terzi et al. [14] showed in a ventilated pig model that in the supine position, the mean difference between $P_{\text {oes }}$ and $P_{\mathrm{L}, \mathrm{D}}$ was $2.2 \mathrm{cmH}_{2} \mathrm{O}$ and between $P_{\text {oes }}$ and $P_{\mathrm{L}, \mathrm{ND}}$ was $7.2 \mathrm{cmH}_{2} \mathrm{O}$ at $10 \mathrm{cmH}_{2} \mathrm{O}$ PEEP. Interestingly, whereas the prone position did not modify the gradient between $P_{\text {oes }}$ and $P_{\mathrm{L}, \mathrm{D}}$, the gradient between $P_{\mathrm{oes}}$ and $P_{\mathrm{L}, \mathrm{ND}}$ decreased to $1.8 \mathrm{cmH}_{2} \mathrm{O}$.

PASTICCI et al. [10] have recently investigated pleural pressures in humans, through a chest tube on the surgery side immediately after lung resection of the nondependent lung region in the lateral and supine positions. The main finding of the PAsticci et al. [10] study was that oesophageal pressures were $7.3 \pm 2.8 \mathrm{cmH}_{2} \mathrm{O}$ higher than nondependent pleural pressures in the supine position; however, because the 

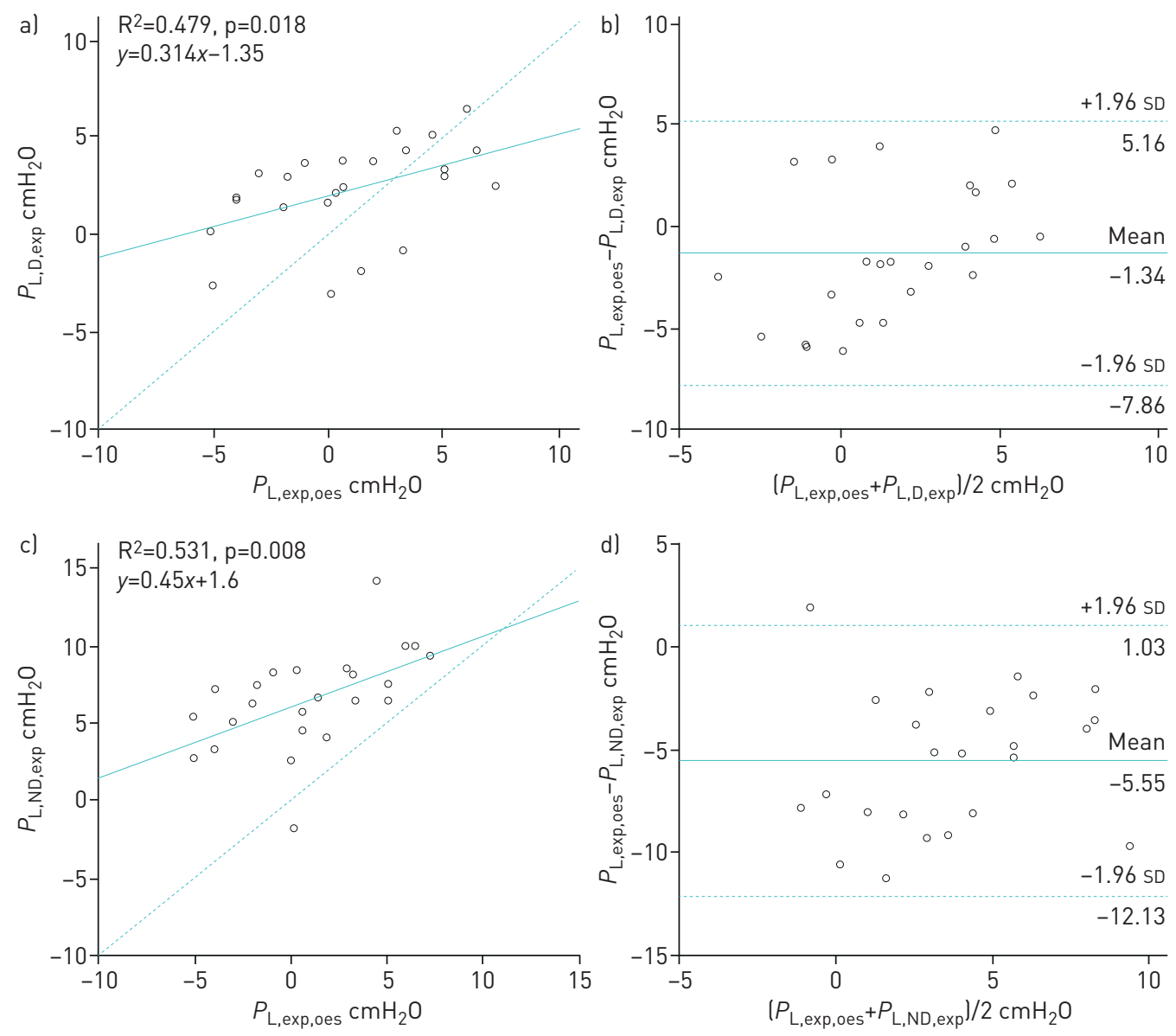

FIGURE 6 a, c) Correlations and b, d) Bland-Altman analysis between transpulmonary pressures calculated using $a, b)$ dependent and $c$, d) nondependent pleural pressure during end-expiration. $a, c, e)$ Dashed line represents the identity line. b, d, f) Solid and dashed lines represent mean \pm 1.96 SD of the differences. Each circle represents a different patient.

change of pleural pressure induced an identical change in oesophageal pressure, the transpulmonary pressures calculated with the elastance ratio methods were perfectly correlated.

Therefore, the principal strength of our study is to confirm and duplicate in a human in vivo setting the results from previous experimental and clinical studies $[3,10,14]$ with the unique characteristic to simultaneously investigate dependent and nondependent pleural pressures and oesophageal pressure.

Minimal discrepancies could be explained by some differences between the models. First, the anatomy of the oesophagus differs in pigs and humans, with a more posterior location in pigs. Second, different cardiac and vascular filling pressures may explain the differences in absolute values of oesophageal pressure observed in lung transplant recipients and cadavers. Third, the pleural pressure sensors were different.

Despite some differences between our model and previous experimental models (animal and cadaver), they also share some common results. In the supine position, the median (IQR) dorsal-to-ventral pleural gradient from the dependent to nondependent lung region was $5.0(2.7-6.4) \mathrm{cmH}_{2} \mathrm{O}$ at inspiration and 4.4 $(1.9-5.6) \mathrm{cmH}_{2} \mathrm{O}$ at expiration in our study, which is very close to the values measured in pigs $(4.4$ $(2.4-6.8)_{\mathrm{cmH}_{2} \mathrm{O}}$ [14], but lower than those measured in cadavers $\left(\mathrm{n}=3\right.$; mean $\pm \mathrm{sD} 10.0 \pm 3.1 \mathrm{cmH}_{2} \mathrm{O}$ ) [3]. In this latter experiment, despite the "Thiel method" to restore elasticity of the tissues, it is possible that the model affects chest wall recoil force compared with humans.

The elastance-derived method to assess transpulmonary pressure $\left(P_{\mathrm{L}, \text { insp,ER }}\right)$ found very close values to those directly measured by $P_{\mathrm{L}, \mathrm{ND} \text {,insp. }}$. These findings are concordant with experimental results and therefore suggest that $P_{\mathrm{L}, \text { insp,ER }}$ could be a valuable target to prevent regional stress and strain of nondependent lung regions [3]. 

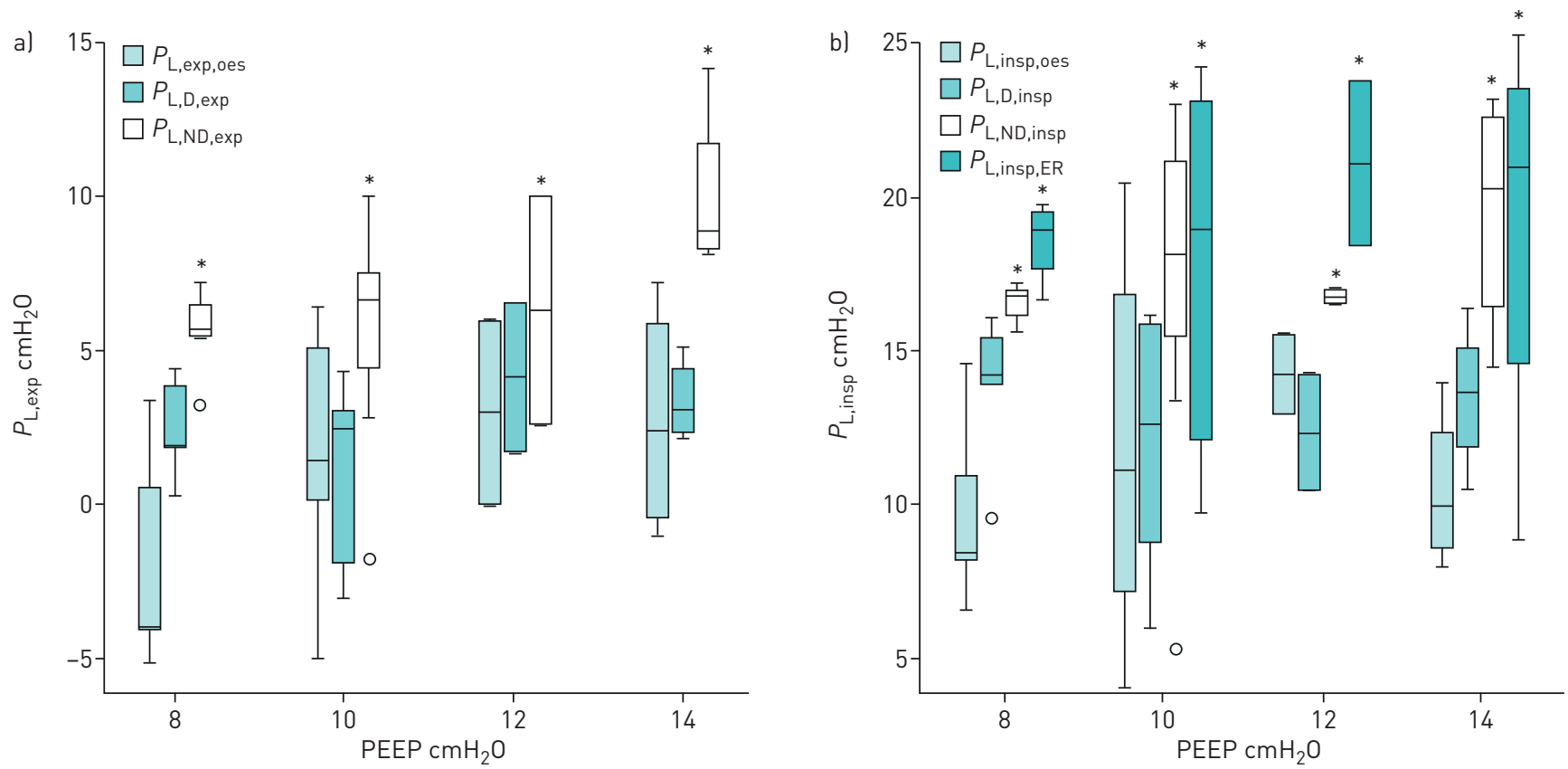

FIGURE 7 Relationship of transpulmonary pressures calculated from oesophageal pressure and pleural pressures in mechanically ventilated human lung transplant recipients during a) expiratory time and b) inspiratory time at different positive end-expiratory pressure (PEEP) levels. *: p<0.05 compared with $P_{\text {oes }}$ and the dependent catheter by the post hoc Bonferroni test. Boxes represent median and interquartile range; whiskers represent minimum-maximum range. Outliers are represented by circles. See Methods for definitions and calculations.

There are several limitations to the present study. First, we used a very specific in vivo model of mechanically ventilated patients with some of them presenting acute lung injury following lung transplantation (primary graft dysfunction). Second, after open chest surgery, the presence of chest tubes, even clamped with no vacuum, may have created some artefacts in the pleural pressure signal. Third, we used common pleural catheters to measure pleural pressure and not specific flat balloon pleural sensors, which have only been used for animal studies so far. However, this was the only device allowed by the French drug safety administration for the study.

Finally, even if oesophageal pressures were well correlated with pleural pressures, we found a significant bias of agreement between oesophageal pressures and nondependent pleural pressures of $5.25 \pm 2.51 \mathrm{cmH}_{2} \mathrm{O}$ at expiration time and $6.09 \pm 2.90 \mathrm{cmH}_{2} \mathrm{O}$ at inspiration time. Of note, a noninferior bias of agreement of $7.2 \pm 5.56 \mathrm{cmH}_{2} \mathrm{O}$ was also reported in a pig model under strict experimental conditions [14].

Although of potential clinical interest, oesophageal manometry is still very underused in clinical practice in ARDS patients $(0.8 \%$ in the cohort of all ARDS patients in the LUNG SAFE study and $1.2 \%$ for severe ARDS patients) [15]. Recently, the largest trial (EPVent-2 study) using oesophageal manometry in ARDS patients failed to demonstrate outcome benefit targeting expiratory transpulmonary pressure compared with a strategy of high PEEP based on a PEEP/inspiratory oxygen fraction table [16].

Oesophageal manometry may be still of clinical interest in specific ARDS clinical vignettes, notably when abdominal or chest wall elastance is increased [17] or in unrecognised harmful strong respiratory efforts $[18,19]$. Oesophageal manometry also remains useful to diagnose patient-ventilator asynchrony which may worsen the outcome [20-22].

In conclusion, in ventilated lung transplant recipients, oesophageal manometry was well correlated with direct measures of pleural pressure with nonspecific sensors and the absolute values were close to those from the dependent lung. During controlled ventilation without respiratory muscles activity, the absolute value of $P_{\text {oes }}$ is higher than the pleural pressure of nondependent lung regions and could therefore underestimate the highest level of lung stress in nondependent lung regions. In addition, the elastance-derived method seems useful to prevent this pitfall.

Acknowledgements: The authors thank the participating patients, the team of the thoracic surgery and the anaesthetic departments involved in the study, Anderson Loundou (Aix-Marseille University, Marseille, France) for his statistical advice on the draft manuscript, and Benoit D’journo (Hôpital Nord, Marseille, France) and Marc Gainer (Aix-Marseille University, Marseille, France) for their comments. 
Conflict of interest: A. Tilmont has nothing to disclose. B. Coiffard has nothing to disclose. T. Yoshida has nothing to disclose. F. Daviet has nothing to disclose. K. Baumstarck has nothing to disclose. G. Brioude has nothing to disclose. S. Hraiech has nothing to disclose. J-M. Forel has nothing to disclose. A. Roch has nothing to disclose. L. Brochard reports grants from Medtronic Covidien, grants and nonfinancial support from Fisher Paykel, nonfinancial support from Sentec, Philips and Air Liquide, and other support from General Electric, outside the submitted work. L. Papazian reports grants and personal fees from Air Liquid, personal fees from Faron, grants from SEDANA and personal fees from MSD, outside the submitted work. C. Guervilly reports personal fees from Xenios Fresenus Medical Care and MSD outside the submitted work.

Support statement: A grant of EUR 13650 from Assistance Publique-Hôpitaux de Marseille covered the material costs of the study. Funding information for this article has been deposited with the Crossref Funder Registry.

\section{References}

1 Fan E, Del Sorbo L, Goligher EC, et al. An Official American Thoracic Society/European Society of Intensive Care Medicine/Society of Critical Care Medicine Clinical Practice Guideline: Mechanical Ventilation in Adult Patients with Acute Respiratory Distress Syndrome. Am J Respir Crit Care Med 2017; 195: 1253-1263.

2 Talmor D, Sarge T, Malhotra A, et al. Mechanical ventilation guided by esophageal pressure in acute lung injury. N Engl J Med 2008; 359: 2095-2104.

3 Yoshida T, Amato MBP, Grieco DL, et al. Esophageal manometry and regional transpulmonary pressure in lung injury. Am J Respir Crit Care Med 2018; 197: 1018-1026.

4 Mojoli F, Chiumello D, Pozzi M, et al. Esophageal pressure measurements under different conditions of intrathoracic pressure. An in vitro study of second generation balloon catheters. Minerva Anestesiol 2015; 81: 10.

5 Baydur A, Behrakis PK, Zin WA, et al. A simple method for assessing the validity of the esophageal balloon technique. Am Rev Respir Dis 1982; 4: 788-791.

6 Gattinoni L, Chiumello D, Carlesso E, et al. Bench-to-bedside review: chest wall elastance in acute lung injury/ acute respiratory distress syndrome patients. Crit Care 2004; 8: 350-355. .

7 Washko GR, O'Donnell CR, Loring SH. Volume-related and volume-independent effects of posture on esophageal and transpulmonary pressures in healthy subjects. J Appl Physiol 2006; 100: 753-758.

8 Talmor D, Sarge T, O'Donnell CR, et al. Esophageal and transpulmonary pressures in acute respiratory failure. Crit Care Med 2006; 34: 1389-1394.

9 Milic-Emili G, Petit JM. Relationship between endoesophageal and intrathoracic pressure variations in dog. J Appl Physiol 1959; 14: 535-537.

10 Pasticci I, Cadringher P, Giosa L, et al. Determinants of the esophageal-pleural pressure relationship in humans. J Appl Physiol 2020; 128: 78-86.

11 Ranieri VM, Giuliani R, Mascia L, et al. Chest wall and lung contribution to the elastic properties of the respiratory system in patients with chronic obstructive pulmonary disease. Eur Respir J 1996; 9: 1232-1239.

12 Terragni P, Mascia L, Fanelli V, et al. Accuracy of esophageal pressure to assess transpulmonary pressure during mechanical ventilation. Intensive Care Med 2017; 43: 142-143.

13 Kassis EB, Loring SH, Talmor D, et al. A fixed correction of absolute transpulmonary pressure may not be ideal for clinical use: discussion on "Accuracy of esophageal pressure to assess transpulmonary pressure during mechanical ventilation". Intensive Care Med 2017; 43: 1436-1437.

14 Terzi N, Bayat S, Noury N, et al. Comparison of pleural and esophageal pressure in supine and prone position in a porcine model of acute respiratory distress syndrome. J Appl Physiol 2020; 128: 1617-1625.

15 Bellani G, Laffey JG, Pham T, et al. Epidemiology, patterns of care, and mortality for patients with acute respiratory distress syndrome in intensive care units in 50 countries. JAMA 2016; 315: 788-800.

16 Beitler JR, Sarge T, Banner-Goodspeed VM, et al. Effect of titrating positive end-expiratory pressure (PEEP) with an esophageal pressure-guided strategy vs an empirical high PEEP- $F_{\mathrm{IO} 2}$ strategy on death and days free from mechanical ventilation among patients with acute respiratory distress syndrome: a randomized clinical trial. JAMA 2019; 321: 846-857.

17 Quintel M, Pelosi P, Caironi P, et al. An increase of abdominal pressure increases pulmonary edema in oleic acid-induced lung injury. Am J Respir Crit Care Med 2004; 169: 534-541.

18 Mauri T, Langer T, Zanella A, et al. Extremely high transpulmonary pressure in a spontaneously breathing patient with early severe ARDS on ECMO. Intensive Care Med 2016; 42: 2101-2103.

19 Yoshida T, Torsani V, Gomes S, et al. Spontaneous effort causes occult pendelluft during mechanical ventilation. Am J Respir Crit Care Med 2013; 188: 1420-1427.

20 Thille AW, Rodriguez P, Cabello B, et al. Patient-ventilator asynchrony during assisted mechanical ventilation. Intensive Care Med 2006; 32: 1515-1522.

21 Blanch L, Villagra A, Sales B, et al. Asynchronies during mechanical ventilation are associated with mortality. Intensive Care Med 2015; 41: 633-641.

22 Bourenne J, Guervilly C, Mechati M, et al. Variability of reverse triggering in deeply sedated ARDS patients. Intensive Care Med 2019; 45: 725-726. 